\title{
SITUAÇÃO HISTÓRICA E CONCEPÇÕES POÉTICAS DE HEINRICH BÖLL
}

Paulo Astor Soethe*

\section{Introdução}

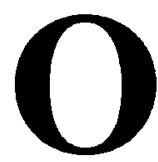

presente artigo pretende apresentar ao leitor brasileiro uma visāo de conjunto das concepções poéticas do escritor alemão Heinrich Böll, desenvolvidas por ele ao longo de duas décadas, em difcrentes ensaios.

Nascido em 1917, Böll assumiu papel central na cena literária alemã do Pós-guerra. Sua obra ficcional voltou-se à representação do quotidiano dos cidadãos alemães, sob a perspectiva dos conflitos morais e éticos vividos nos contextos de miséria, reconstrução e esplendor sócio-econômicos da sociedade alemã ocidental. Sua narrativa simples, mas inventiva, atenta e perspicaz, encontrou grande repercussão junto a leitores alemães e estrangciros. A tiragem total de seus livros, traduzidos para mais de trinta idiomas, alcançou a marca de vinte milhōes de exemplares, alguns dos quais, entre 1968 e 1987, integraram a cena literária em nosso país.'

A atenção ao contexto imediato $\mathrm{cm}$ que surgem e a relevância mais abrangentc que acabam obtendo são traços comuns entre os textos ficionais $\mathrm{c}$ as

*Universidade Federal do Paraná.

${ }^{1}$ Para maiores informaçōes sobre a recepção de Heinrich Böll no Brasil, v. SOETHE, Paulo. “. 'Nele tem-se a impressão de que amargura rima com travessura. Contribuição bibliográfica ao estudo da recepção de Heinrich Böll no Brasil." Revista de Ciências Humanas, Curitiba, n. 3, p. 105-11, 1994. 
reflexões poéticas de Böll. Embora preocupado com a produção literária especifica de seu tempo, os ensaios do escritor apresentam argumentos instigantes, que os tornam ainda hoje dignos de análise. Em consideração a esse duplo caráter dos textos analisados, o artigo apresentará de início o contexto vivido pelo autor, para a seguir discorrer sobre suas concepções poéticas.

\section{Situação histórica e literária}

Heinrich Böll e seus contemporâneos constituíram uma geração de homens $\mathrm{e}$ mulheres assinalados de forma irremediável pela Segunda Grande Guerra. Suas vivências, após o fim do conflito, em 1945, foram marcadas pela misćria material, pela submissão à presença maciça de exércitos estrangeiros, pela descoberta da inconsistência e absurdo das crenças políticas do passado $\mathrm{e}$ pelo pasmo diante das atrocidades cometidas durante a guerra (para alguns até então desconhecidas). Os aliados encontraram na Alemanha vencida uma população civil esgotada pelo longo período de guerra, indiferente e apática face à situação irremediável de destruição e perdas. As primeiras experiências espontâneas de rcorganização social limitaram-se à troca de artigos de higiene e limpeza, alimentos e cigarros, comercializados no mercado negro. $O$ caos cconômico e político em que a Alemanha se encontrava demarcava o fím do estado hitlerista. $^{2}$

Dos soldados do Reich, além dos três milhôes e oitocentos mil que haviam morrido em combate, cerca de sete milhöes estiveram condenados a habitar durante meses os campos de prisioneiros, mesmo após o final da guerra. Muitos nem sequer voltaram; a maior parte, no entanto, foi sendo pouco a pouco reintegrada a seus lares e familias, quando estes ainda existiam. Além dos soldados, outros doze milhōes de civis vinham do leste, na condição de fugitivos, obrigados a deixar sua terra natal. Traziam o mínimo consigo, e poucas vezes encontravam de imediato portas abertas nas cidades e aldeias já bastante sacrificadas pela guerra. A reconstrução de uma nova vida a partir do nada viria a ser a tarefa de muitos.

Às imagens da destruição das grandes cidades - Dresden é epigramática nesse sentido -, pouco a pouco aliaram-se outras, de mulheres sobre escom-

${ }^{2}$ Sobre a história do período imediatamente posterior ao fim da guerra na Alemanha, $v$. BIRKE, Adolf M. Nation ohne Haus. Deutschland 1945-1961. Berlim: Siedler, 1989 e GLASER, Hermann. Kleine Kuluturgeschichte der Bundesrepublik Deutschland. Munique: Carl Hanser, 1991. 
bros, retirando dos montes amorfos as pedras para a reconstrução. ${ }^{3} \mathrm{Da}$ sociedade c de cada indivíduo restavam fragmentos a se recompor; da língua alemã, palavras, estruturas, enunciados ditos e contidos a revitalizar.

Dali a alguns anos, na década de 50, a Alemanha da catástrofe e da destruição se tornaria outra. Já em 1948 as zonas ocupadas pelas forças militares ocidentais (inglesa, norte-americana e francesa) passaram a viver uma fase de surpreendente revitalização econômica. A reforma monetária, daquele mesmo ano, o fortalecimento da proposta de Ludwig Erhard para uma economia de mercado social (concep̧̧ão sustentada politicamente pela União Democrática Cristã) e os investimentos maciços proporcionados pelo plano Marshall de recuperação econômica para a Europa abriram caminho para o crescimento econômico e para a reconstrução. Superar (ou simplesmente esquecer) o passado e reestruturar uma sociedade democrática, rica $\mathrm{c}$ bem-sucedida era palavra de ordem para a jovem República Federal da Alemanha, fundada em 1949 sob o comando democrata-cristão de Konrad Adenauer.

O futuro acenava com um sorriso otimista, mas para alguns excessivamente maquiado e não suficientemente inovador. Uma geração de jovens intelectuais, à qual Heinrich Böll pertencia, caracterizava-se por ser na época "jovem o bastante para crer no novo $\mathrm{e}$ velha o bastante para reconhecer $\mathrm{e}$ temer os perigos da Restauração".

No caso de Böll, são justamente as vivências de crença e esperança, de um lado, e de crítica e prevenção, de outro, que marcarão de forma particular sua produção litcrária c ensaística. Elc alcançará muitos dos pontos altos em sua obra ao compor um mosaico literário em que se misturam um otimismo profético de caráter humanista e popular e um excrcício sistemático de crítica à sociedade alemã e a suas motivações a partir da reconstrução.

Quando o nacional-socialismo havia se consolidado como regime oficial na Alemanha, Böll contava 15 anos de idade. No primciro período de maturação intelectual, vivia portanto em uma sociedade rigidamente controlada, em que não havia liberdade de pensamento e expressāo, c que se preparava inevitavelmente para a guerra. Por provir de uma familia simples, marcada pela tradicional resistência renana aos regimes autoritários (como o prussiano, por exemplo) e pelo cultivo de uma identidade católica igualmente distante do eventual autori-

3 A proporção de mulheres para homens nas zonas ocupadis era de 100 para 80 (BIRKE, op. cit., p. 30). O filme “Deutschland, bleiche Mutter", de Helena Sanders-Brahms, 35 mm, cor, 145 min, 1979, apresenta, sob o enfoque feminino, um quadro representativo dos dramas vividos pelas mulheres alemãs durante e ao fim da Segunda Guerra Mundial. Imagens autenticas das cidades destruídas e do trabalho de reconstrução executado pelas "Trümmerfrauen" são um excelente recurso utilizado pela diretora, que confere ao filme também especial interesse histórico.

FRIEDRICHSMEYER, Die satirische Kurzprasa Heinrich Bölls. Chapell Hill: The University of North Carolina Press, 1981, p. 18. 
tarismo de Roma, ${ }^{5}$ Böll manteve-se crítico e distante em relação ao regime de Adolf Hitler.

Em 1939, no entanto, foi convocado pelo exército e mandado ocasionalmente para ofront. Chegou a simular doenças para obter dispensas do serviço, a desertar por algumas semanas, logrando manter-se despercebido das autoridades, com documentos falsos. A situação de deserção tornou-se, porém, insustentável, e Böll viu-se obrigado a reintegrar-se ao exército. Alguns meses depois, encontrava-se preso em um campo de prisioneiros na França. Em 1945 retornou a sua cidade natal e passou então a dedicar-se à literatura.

O jovem escritor, assim como seus contemporâncos, vê-se entretanto face a uma situação bastante peculiar. Seu país havia rompido, nos doze anos de regime nacional-socialista, com o percurso artístico e literário característico nos demais países ocidentais. A modemidade cultural havia sido malvista pelo poder vigente, que tratara a arte daquele início do século XX como "degenerada" e restringira severamente o acesso do público alemão a ela. Uma das providências dos aliados após o fim da guerra, para se ter uma idéia, foi promover exposiçōes de certo tipo de obras de arte com o qual os alemães já não tinham qualquer intimidade: é o caso da mostra itinerante francesa La peinture française moderne, que percorreu várias cidades da Alemanha, chegando a Berlim em outubro de $1946 .^{7}$

No que diz respeito à palavra escrita, a situação não havia sido outra. É significativa a queima pública de livros "não-alemães”, promovida já em 1933 pelos nazistas. Obras como as de Sigmund Freud, Karl Marx, Franz Werfel e Franz Kafka haviam sido proscritas e condenadas ao fogo pelo regime.

Muitos escritores em atividade - tais como Heinrich e Thomas Mann, Bertolt Brecht c Alfred Döblin - tiveram que deixar o país e buscar o exílio. Suas obras foram igualmente proibidas.

Outros autores, que oplaram por permanecer na Alemanha mesmo sem gozar de liberdade ou prestígio, praticaram o que se designaria mais tarde "emigração interior": alguns abandonaram temporariamente a literatura, aguardando a derrota de Hitler; outros limitaram-se a escrever sem publicar; outros ainda produziram textos de caráter subjetivo e metafísico, abordando temas que não chegavam a despertar restrições por parte do poder vigente. Entre cles podem ser citados Ernst Jünger e Gertrud von Le Fort.

${ }^{5}$ Sobre a questão v. KUSCHEL, Karl-Josef. Heinrich Böll e a visão de uma catolicidade diferente. Síntese, Belo Horizonte, v. 21, n. 67, p. 539-57, 1994.

${ }^{6}$ HOFFMANN, Gabricle. Heinrich Böll. Leben und Werk. Munique : Wilhelm Heyne, 1991.

${ }^{7}$ BIRKE, op. cit., p. 92. Obras de Renoir, Picasso, Dali e Utrillo, entre outros, integravam a mostra. 
Ainda um terceiro grupo de escritores identificou-se com o regime e produziu textos "edificantes", no sentido das idéias oficiais do nazismo, em que se louvavam os valores e os feitos da nação germânica. Hanns Johst e Erwin Guido Kolbenheyer são alguns entre eles. Sua atividade caiu em total descrédito político e intelectual, sobretudo após o processo de desnazificaçāo promovido pelas forças aliadas: para se evitar o ressurgimento do nacional-socialismo na Alemanha, cada cidadão teve seu passado posto em questão através de formulários, declaraçōes de terceiros e investigaçōes específicas. Quanto menos a pessoa tivesse estado envolvida com o regime, tanto mais gozaria de confiança da administração estrangeira e tanto maiores seriam suas facilidades de reintegração na organização social emergente. Toda a atmosfera cultural, política e administrativa proporcionada pelos aliados tencionava opor-sc à barbáric vivida pelos alemães no passado recente.

Submetida por doze anos à voz oficial da ditadura, a língua alemã, segundo alguns, precisaria ser "reinventada" para a literatura e para a livre criação. Essa posição inovadora e programática foi assumida como tal por um grupo de jovens escritores preocupados $\mathrm{cm}$ se firmar como nova geração literária.

Eles se opuseram tanto estética quanto politicamente ao panorama intelectual que pretendia firmar-se na Alemanha do Pós-guerra. Havia no país, por parte da geração mais velha, a tendência de retomar uma herança espiritual subjetivista e idealista, que lançava raizes no século XIX. Como sinal de rechaçamento a posteriori da barbárie hitlerista, o intelectual alemão médio pretendeu cultivar valores da cultura alemã que considerava autêntica c que teria sido potencialmente conservada, à revelia dos acontecimentos politicos entre 1933 e 1945. A população acusada de constituir-se de "Richter und Henker" (juizes e carrascos) preferia assumir o papel de um povo de "Dichter und Denker" (poctas c pensadores). ${ }^{8}$

A retomada imediata de antigos valores do espírito alemão, porém, não satisfazia muitos intelectuais da geração mais jovem. Eles estavam atentos, sim, às ruínas e às conseqüèncias políticas e sociais do que fora a "boa cultura alemã" do passado. Seu julgamento voltou-se para o que tinham concretamente diante de si. E a apreciação não foi complacente. Os textos ficcionais de cunho nacional-socialista sequer foram considerados literários, e seus autores, execrados. A chamada "emigração interior" foi vista como sinal de covardia e acomodação velada ao sistema. Os escritores do exilio, ainda que tivessem alcançado reconhecimento internacional, foram considerados distantes e sem vinculos mais imediatos com a realidade concreta do público na Alemanha.

${ }^{8}$ GLASER, op. cit., 1991, p. 15. 
Caberia à nova geração, portanto, e segundo ela mesma, considerar o momento do Pós-guerra a "hora zero", o ponto inicial para se estabelecer os novos caminhos da produção literária alemã. Era como se lhes coubesse fundar novamente a literatura em língua alemã.

Marcados por esse espírito, alguns escritores organizaram uma série de encontros a partir de setembro de 1947, prontos a discutir as novas possibilidades estéticas para a literatura a ser produzida na Alemanha do Pós-guerra. Surgia, sob a iniciativa de Hans Werner Richter, o Grupo 47, responsável pelo lançamento e consagração de muitos dos jovens escritores alemães que fariam sucesso nas décadas seguintes, dentre os quais o próprio Heinrich Böll. ${ }^{9}$ Segundo este último, o Grupo 47 teria sido um ponto de encontro para os jovens intelectuais, uma academia capaz de mover-se no espaço, um substituto para a capital literária de que o país não dispunha. Lá o pluralismo de idéias teria sido praticado muito antes de se tornar moda na Alemanha. ${ }^{10}$

Quanto à postura assumida pelo Grupo, são csclarecedoras as palavras de Richter:

Face à imagem enegrecida pela fumaça das paisagens de ruínas do Ocidente (...) ficam empalidecidos todos os parâmetros de valores do passado. Qualquer possibilidade de ligação com o que estava para trás, qualquer tentativa de retomar aquele ponto no qual em 1933 uma geração mais velha havia abandonado sua linha de desenvolvimento, para capitular diante de uma aventura irracional, qualquer iniciativa desse tipo soa como paradoxo diante daquela imagem. ${ }^{11}$

A situação, porém, não era tão simples e unilateral como a descrita acima. Segundo estudos recentes e mais isentos, não ć historicamente coerente apregoar a existência da "hora zero". Muito menos aceitar a idéia de que se pudesse reiniciar a literatura alemã a partir de um rompimento drástico com a tradição. Muitos cscritores do passado continuavam escrevendo e eram bem recebidos pelo público alemão da época. Além disso, a recep̧̧ão de clássicos, desde Goethe

\footnotetext{
${ }^{9}$ Vasta documentação sobre o Grupo 47 encontra-se em LETTAU, Reinhardt (org.). Die Gruppe 47. Bericht, Kritik, Polemik. Neuwied: Luchterhand, 1967.

10."Angst vor der 'Gruppe 47"'. In: BÖLL, Heinrich. Werke. Essaystische Schriften und Reden (Obras completas. Escritos e discursos ensásticos). 3 v. Colönia: Kicpenheuer und Witsch, 1979, v. 2, p. 163-73. (Doravante os trés volumes serão indicados, respectivamente, por ESR 1, ESR2, ESR3, seguidos do número da página em questão.)

${ }^{11}$ Hans Werner Richter, apud VORMWEG, Heinrich. Deutsche Literatur 1945-1960: Keine Stunde Null. In: DURZAK, Manfred (org.). Deutsche Gegenwartsliteratur. Ausgangspositionen und aktuelle Entwicklungen. Stuttgart: Reclam, 1981, p. 20.
} 
e Schiller a Rainer Maria Rilke, dava-se também em larga escala. Mais aceitável - e isso é o que importa para o presente artigo - seria entender a incorporação de tais conceitos à historiografia da literatura alemã por força mesmo da vitória política e ideológica obtida pela geração mais jovem. Por sua maior agressividade e senso de organização mais acurado, essa geração, articulada em torno do Grupo 47, teria obtido maior receptividade junto ao público e às editoras e feito prevalecer sua própria visão c ideário no panorama literário alemão da época.

Heinrich Vormweg, em capitulo sobre a literatura alemã do periodo, é bastante categórico no que diz respeito a esse ponto. Em sua opinião, "não houve para a literatura alemã qualquer 'hora zero". $O$ novo, o que há de mais verdadeiro em cada época, pode tomar forma somente a partir da consciência de sua realidade e da consciência de todas as possibilidades que oferece." 12

Desse modo, Vormweg procura explicar a consolidação do ideário da jovem geração de escritores alemães entre 1945 e 1960 a partir de uma motivação existencial e moral: "No início desta fasc [da literatura alemā] está um impulso impetuoso, existencial e moralmente motivado: o impulso de proferir o que há de verdadeiro, a verdade mesmo; ele conduziu de imediato à questão das possibilidades da linguagem para proferir essa verdade."13

Tal impulso, como veremos, é especialmente significativo para a compreensão das reflexões poéticas desenvolvidas por Böll, ainda que sua participação efetiva nas atividades do Grupo 47 tenha sido pequena. Segundo R. W. Leonhardt, ${ }^{14}$ Böll teria comparecido "por gratidão" a algumas poucas reuniões e teria feito apenas uma leitura pública além daquela de 1951 , quando o Grupo 47 conferiu a ele um prêmio literário pela autoria de "As ovelhas negras" (“Die schwarzen Schafe"). A gratidão de Böll seria não só pelos 1.000 marcos em dinheiro que havia recebido por ocasião desse prêmio, mas mais ainda pela popularidade que seu nome obteve a partir dai no cmergente mercado literário alemão.

Ainda que tivesse mantido sua peculiar independéncia $\mathrm{cm}$ relaçāo a grupos organizados, Böll demonstrou com sua rápida participação no Grupo 47 estar mergulhado nas questões de seu tempo e de seus pares. Juntos, eles constituiam uma geração alerta aos deslizes do passado e às suas possíveis reedições no presente.

É esse o contexto em que Heinrich Böll passa a atuar de forma intensa, face a um quadro polèmico de transformações sociais, culturais e políticas. Após reccber o prêmio do Grupo 47, já estava "feito literariamente" ${ }^{\text {"15 }}$ e dispunha de

${ }^{12}$ VORMWEG, op. cit., p. 30.

${ }^{13}$ Ibid., p. 29.

${ }^{14}$ LEONHARDT, Rudolf Walter. Aufstieg und Niedergang der Gruppe 47. In: DURZAK, 1981, p. 67.

15 .....war er literarisch gemacht", cf. KURZ, Paul Konrad. Uber moderne Literatur. 2. ed. Frankfurt a. M.: Josef Knecht, 1976, v. 3, p. II. 
lastro cultural para manifestar suas idéias, de forma que elas obtivessem repercussão sempre crescente junto à opinião pública.

\section{Concepções poéticas: a estética do humano}

É de maio de 1952 o primeiro texto em que Böll expressa posições definidas sobre o papel do escritor e sobre as tarefas e especificidades da literatura: trata-se de Profissão de fé para uma literatura de escombros.

Afirma-se, nele, a identificação entre o literato e as experiências da população no período imediatamente posterior ao fím da guerra. Böll afirma accitar a designação “literatura de escombros”, atribuída a sua produção e à de sua geração, mas rejeita o tom de desmerecimento com que teria sido feita. Confessa não poder "defender-se" de tal designação, simplesmente pelo fato de ela corresponder à realidade: da mesma forma que a população local c aqueles que retornavam da guerra, os escritores teriam visto a realidade, sem omitir-se em jogos irresponsáveis, tal como estariam fazendo muitos alemães, dedicandose à leitura dos clássicos e ao cultivo do mundo indevassável do espírito. A defesa da geração de jovens escritores, no texto, indica a identificação de Böll com seus pares, c está cm sintonia com o processo de auto-afirmação assumido pelo Grupo 47.

Nesse sentido, o texto apresenta Charles Dickens como escritor que também teria visto os problemas de seu tempo e sc posicionado através de sua literatura em relação a cles - "um bom olho está entre as ferramentas do escritor" (ESR1, p. 33). Com sua literatura, Dickens teria provocado mudanças sociais e obtido, assim, uma vitória poucas vezes vivida pelos literatos - mas evidentemente desejada por Böll.

Os escritores vêem a realidade em torno de si com olhos livres. E por isso, ao se deparar com a cidade e scus habitantes, percebem que estes últimos não apenas moram nela, mas são também administrados pela burocracia que a move. Face a isso impõe-se ao escritor a tarefa de "lembrar que o homem não existe apenas para ser administrado". Cabe-lhe destacar o componente humano - e portanto livre e inadministrável - do homem.

A recusa da burocracia emergente possui um sentido particular para o ideário de Böll. O fim do caos do Pós-gucrra e a restauração das relações burguesas na sociedade alemã tiveram suas marcas visívcis na consolidação de uma nova organização burocrática. A mudança da moeda, em 1948, é mesmo um marco na história da República Federal da Alemanha. Ela assinalou a op̧̧ão por uma cconomia de livrc mercado, o que frustrava o desejo do escritor de ver scus projetos utópicos realizados na Alemanha. Para cle, assim como para 
muitos outros intelectuais, a nova organização econômica consolidava a ameaça de que o país deixasse de assumir caminhos alternativos em sua história. Começavam a tornar-se inviáveis os planos de construção de uma sociedade baseada na solidariedade e fundamentada sobre principios socialistas de matizes cristãos. ${ }^{16}$ Böll manifestou-se anos mais tarde de forma bastante contundente sobre a reincidência " $\mathrm{cm}$ uma nova sociedade baseada na propriedade privada $\mathrm{e}$ no egoísmo familiar." Para ele, a consolidação de tal sociedade deu-se pelo fato de que "os alemães não aceitaram o que hoje se denomina derrota e fracasso e nem souberam reconhecer neles uma nova chance". ${ }^{17}$

Dessa forma, tornaram-se irreconciliáveis as opções políticas e éticas de Böll e a estruturação social que se firmara como vitoriosa. Ao escritor segundo sua própria formulação em textos posteriores - restaria apenas recorrer às reservas de humanidade ainda existentes na vida de pessoas simples e desconsideradas socialmente.

Em Profissão de fé para uma literatura de escombros, tal recurso já se antecipa nas menções a um padeiro e a uma jovem trabalhadora. As duas figuras surgem no texto como representantes da geração de pessoas humildes marcadas pela guerra. A caracterização de ambos constitui um primeiro passo para a determinação da categoria ética e poética central em toda a obra de Böll: a categoria do humano. $O$ padeiro e a jovem são no texto o ponto de referência para o estabelecimento dos compromissos do escritor: o comprometimento do literato não se limitaria ao engajamento político imediato, determinado por um único momento histórico. Böll até mesmo refutará, anos mais tarde, a distinção entre literatura engajada e literatura pura, que tomou corpo nas discussões dos anos 60 e $70 .^{18}$ Sua reflexão parece buscar o humano enquanto elemento constitutivo da própria literatura, apresentado como marca de sua inserçāo na vida e portanto nas relações entre os homens.

Do padeiro, por exemplo, diz-se que é "antigo como o mundo". O escritor contemporânco o vê trabalhando, "tal como Homero o viu, tal como os olhos de Balzac e Dickens não o deixaram passar despercebido", cada qual a seu tempo

${ }^{16}$ A importância programática que esse projeto social assume para o jovem Böll é demonstrada por sua contribuição regular ao "Cademos de Frankfurt", um dos principais veiculos do catolicismo progressista na Alemanha. O papel de Böll para o catolicismo alemão é detalhadamente abordado em GOTTLICHER, Kerstin. Dic irdisch-materialistische, menschlich-himmlische Leni: Aspekze der Religion in Heinrich Bölls Roman "Gruppenbild mit Dame". Giessen, 1990. Magisterarbeit - Justus-Liebig-Universität. À atuação de Böll dedica-se também uma seção exclusiva na bibliografia organizada por Hehl c Hürten sobre o catolicismo alemão entre 1945 c 1980 ( $v$. HEHL, Ulrich von; HORTEN, Heinz (orgs.). Der Katholizismus in der Bundesrepublik Deutschland 1945-1980. Eine Bibliographie. Mainz, 1983.)

${ }^{17}$ Citado por BALZER, Bernd. Heinrich Bölls Werke: Anarchie un Zärtlichkeit. In: BOLL, Heinrich. Werke. Romane und Erählungen. ed. cit., p. [41].

18 ..(...) Parece-me uma atitude suicida discutirmos continuadamente a distinção entre literatura engajada e uma outra literatura, qualquer que seja." (ESR3, p. 48) 
(ESR 1, p. 33). Por um lado Böll afirma a permanência do humano no decorrer da história; por outro, a indissociabilidade entre esse humano $\mathrm{c}$ sua inserção no tempo histórico assumem para ele um status privilegiado.

Estes dois, o padeiro e a moça, pertencem a nosso tempo, estão suspensos no tempo; datas estão entrelaçadas $\mathrm{cm}$ torno deles como uma rede; tirá-los dessa rede seria o mesmo que tirar-lhes a vida; o escritor, no entanto, precisa de vida, e quem mais poderia assegurar a vida a esses dois, senão a literatura de cscombros? (ESR1, p. 34)

O "humano" realiza-se em momentos históricos específicos, c através da consciencia da temporalidade a que estão submetidos os indivíduos. Em mcio à rcalidade do Pós-guerra alemão, o escritor vai encontrar vida na paisagem física e psicológica dos escombros, pois ćali quese realizam as relações pessoais que o cercam concretamente. O processo de representação literária, para Böll, deve resgatar a vida dos indivíduos presente na realidade. Essa intenção, contudo, não corresponde à de se construir um quadro fiel da realidade. Não se cogita qualquer neutralidade por parte do escritor. Ver, nos textos de Böll, implica um comprometimento ético. Para ele, nas palavras de Dieter Kafitz:

O escritor está voltado para os acontecimentos do presente, é verdade; mas não apenas os registra e cataloga, e sim os ilumina e interpreta; a literatura torna- $s$ e um complemento necessírio ao humano e capaz de abrir-lhe novas dimensões, cla cria um horizonte de sentido para os acontecimentos superficiais do presente. $^{19}$

A litcratura, portanto, surge do confronto entre o autor e sua realidade, mas este não se limita a representá-la como dado acabado, que possui scus traços cm si mesma. O que o texto literário representa é sua própria gênese e constituição a partir do embatc produtivo e transformador cstabelecido entre o autor c seu meio social, as estruturas de poder $\mathrm{c}$ os demais homens e mulheres com que se relaciona direta ou indiretamente.

Os constantes csforços empreendidos por Böll para apontar os compromissos do escritor, a opção pelas fontes de criação no meio pequeno-burguês,

${ }^{19}$ KAFITZ, Dicter. Formtradition und religiöses Ethos - zur Realismuskonzeption Heinrich Bölls. Der Deutschumerricht, Stuttgart, v. 6. dez. 1976, p. 69. 
sua insistencia $\mathrm{cm}$ assegurar a liberdade e autonomia do escritor diante das estruturas de poder da sociedade e a defesa da inserção da literatura na vida tudo isso constituira permanente objeto de suas preocupaçōes.

A exposiçāo mais extensa e abrangente das concepçōes de Böll sobre literatura encontra-se nas Preleçōes de Frankfurt. Nelas, dedica-se ao cstabelecimento de uma "estética do humano". E comega por evidenciar a importancia que atribui ao cariter social c interativo no processo de constituiçāo do homem:

Parto do pressuposto de que sio a linguagem, o amor e a vinculação que fazem do ser humano um ser humano; parto do pressuposto de que sajo eles que colocam o wer humano $\mathrm{em}$ contato consigo mesmo, com os outros e com Deus monólogo, dialogo, oração. (ESR2, p. 37)

O homem torna-se humano, e sua condiçāo de existéncia firma-se a partir das relações com o outro. Mesmo a relaçāo "consigo mesmo" i vista a partir de um processo de interaçāo com um cu alterizado, mediada pela linguagem. E não são gratuitas, na formulação de um pressuposto tảo fundamental para todo o desenvolvimento da estética do humano, a menção ao "amor", como relação que humaniza o homem, c à "oração", como uso da linguagem que o coloca cm contato com Deus.

Ora, a "hominização do homem" ("dic Menschwerdung des Menschen") - formulação presente nas Preleçōes de Frankfur (ESR2, p. 85) - constitui preocupação recorrente em vários outros ensaios, entrevistas e textos ficcionais de Böll, e assume com freqüència, para o escritor, ocariter de reflexãoteológica. O terno "Menschwerdung", afinal, possui duplo sentido em alemão, pois refere-se, por um lado, ao desenvolvimento do ser humano em geral, c, por outro, à encamação de Deus, na tradição do Novo Testamento. Diversos críticos vêem ai um ponto-chave para o estudo da identificação de Böll com a tradiçāo cristã católica, tanto do ponto de vista literírio quanto tcológico. Boa parte da critica destaca a atuação de Böll como humanista cristão discute a importancia de seu conccito de humanidade para a discussão teológica c eclesiológica contemporânca. ${ }^{20}$

Traços explicitos da herança cristi, como esses, antecipam a soluçäo "comunitaria" e utopica que marcara o estabelecimento da calcgoria do thu-

${ }^{20}$ Hans Küng, um dos mais renomados lexilogen cattilicin, c Walter Jens, escritor c critico) literirio católico, prexemplo, dedicam a Bill cada qual um eapituk em sua wha Defensores dkz humanidade (cf. KONG. Hans; JENS, Walter. Anweilte der Humanirät: Thomas Mann, Hermarm Hesse. Heinrich Böll. Munique: Kindler. 1989.) 
mano" nas Preleções de Frankfurt. As categorias presentes nesse e em outros textos ensaisticos - e que constituirão objeto de sua produção ficcional manifestam reservas $\mathrm{cm}$ relação à estruturação burocratizada e individualista que caracteriza a sociedade estabelecida. Para o crítico Stephan Güstrau:

Böll denomina "hominização" ["Menschwerdung"] o processo, o desenvolvimento de um ser humano em direção a si mesmo, com os outros e diante de Deus. Ele procura tornar-se inteiramente ele mesmo - em confrontação com instituições e relações de dominação que querem submetê-lo à obediência e classificálo como resto [“Abfall”]. Hominização é a visão literária de Böll da vida e da sobrevivência bem-sucedidas em um tempo desumano. A "hominização" é a busca de humanidade. ${ }^{21}$

Esse confronto com as instituições e com o poder explicita-se já no início das Preleções de Frankfurt. $O$ texto desenvolve ampla argumentação em defesa da isenção da literatura no que diz respeito a suas relações com a sociedade organizada ("Gesellschaft"). Sempre que ambas entram em contato, a literatura torna-se "objeto de interesses" (ESR2, p. 35). Sob os efeitos de tal apropriação indevida, a literatura correria o risco de perder sua especificidade e submeter-se ao poder, que esvazia a linguagem de seus significados: "Quanto mais poder, tanto menos expressivo é o vocabulário, palavroso e pouco expressivo" (ESR2, p. 37).

Böll pretende, afinal, denunciar a dissociação entre sociedade organizada ("Gesellschaft") e o que haveria de genuinamente social e humano ("sozial" e "human"):

As palavras "social" e "humano" (...) são evitadas, oprimidas e ridicularizadas $\mathrm{em}$ nossa sociedade ["Gesellschaft"]: clas são socialmente inaptas e associais quando surgem sem um determinante, sem uma cobertura cientifica, como nas palavras Sociologia e Humanismo, ou sem uma cobertura política, como se apresenta na palavra Socialismo. (ESR2, p. 35)

E imediatamentc a seguir:

${ }^{21}$ GOSTRAU, Stephan. Literatur als Theologieersatz : Heinrich Böll: "Sie sagt, ihr Kuba ist hier und auch ihr Nicaragua. " Frankfurt a. M.: Peter Lang, 1990, p. 75. 
Ai de quem procura e encontra qualquer conexão humana entre o religioso e o social que esteja fora dos parâmetros da caridade aceita e organizada em seus mínimos detalhes... - eu não me espantaria se as igrejas se associassem a uma sociedade ["Gesellschaft"] ateista a fim de eliminar uma pessoa ou um grupo que tivesse, por pura confiança em Deus, se abandonado ao humano e näo à sociedade ["Gesellschaft"]. (idem)

Explicita-sc a dicotomia cntre a sociedade estabelecida, vista como desumanizada e dessocializada, e o humano, como categoria alternativa e utópica, a ser concretizada. Ainda segundo Stephan Güstrau, o humano em Böll “incorpora a contrapartida à realidade vivenciada, que não se apresenta ao ser humano como uma terra acolhedora ['Heimat']. O humano é o princípio da literatura de criar essa terra acolhedora." 22

De fato, a palavra "Heimat" assumirá grande importância nas Preleçōes de Frankfurt e caminhará pari passu com a utopia do humano. Pode ser traduzida para o português como "pátria", mas não encontra cortespondência plena nessa palavra, pelo aspecto etimológico. Em alemão existe como correspondente imediato de "pátria" a palavra "Vaterland" ("Vater" = "pai" + "Land" = "terra" ou "país"). "Heimat" ("heim" ["home" em inglês] + "oti") significa literalmente "lugar em que se mora". "Heim" continua presente no alemão contemporânco e equivale a "lar" em português. Assim, mesmo hoje o significado primeiro de "Heimat" é "local em que alguém se sente em casa” e por extensão "local em que se nasce, em que se mora". Böll, ao utilizar essa palavra, mantém viva sua proximidade mais "humana" com "Heim" e com a idéia de "morar", de "sentirse em casa". 23

Pela contraposição entre sociedade estabelecida e humano, percebe-se que, mesmo anos depois da formulação do ensaio Profissão de fi para uma literatura de escombros, permanecem presentes as linhas gerais do ideário defendido por Böll quando ainda movido pela utopia da reconstrução da Alemanha a partir de uma visão de mundo baseada em valores de solidariedade e igualdade. Nas Preleçōes de Frankfurt, o autor lembra explicitamente esse ideário e lança-o como desafio a seus ouvintes, jovens universitários. Segundo ele, a geração dos avós, que havia sobrevivido à guerra e reconstruído o Estado alemão sobre bases burguesas, legaria em breve, diretamente a eles, seus netos, a condução do Estado. Assim:

${ }_{23}^{22} \mathrm{Idcm}, \mathrm{p} .49$.

23 Optou-se aqui por traduzir "Heimat" como "terra acolhedora", a fim de não se perder nem a carga sentimental que a palavra implica, nem sua dimensão social e utópica. 
Vocês conduzirão muito em breve este Estado. Farão dele um Estado do qual se poderá sentir falta como se sente falta de um lar? ["nach dem man Heimweh haben kann?" - grifo nosso] Um Estado que poderá surgir na literatura como componente do humano? Talvez um dia se escreva na forma de um grande romance (...) o que ocorreu aqui entre 1945 e 1950: que houve esta situação única de igualdade, que (...) todos os habitantes deste país não tinham qualquer propriedade, mas possuíam tudo o que lhes caia nas mãos: carvão e madeira, móveis, quadros e livros. (ESR2, p. 75)

É justamente pela manutenção deste ideário - pela preservação da "motivação existencial e moral" da nova geração de escritores após 1945 - que as Preleções de Frankfurt estabelecem seu foco de atenção sobre a "procura por uma linguagem habitável em um país habitável" (ESR2, p. 53). E nessa procura, atribui-se papel central à literatura: segundo Böll, é ela, como atividade livre, independente e insubmissa à sociedade organizada, que deve representar o humano e "criar essa terra acolhedora".

Para isso a produção literária precisará recorrer às reservas de humanidade ainda existentes nas pessoas simples e desconsideradas socialmente: "A humanidade de um país deixa-se reconhecer através do que se deposita em seus restos ['Abfall'], através daquilo de quotidiano, de ainda utilizável, daquilo de poético que é jogado fora e considerado passivel de destruição" (ESR2, p. 71). Além de estabelecer críticas veementes às bases da sociedade alemã da época, Böll volta-se generosamente aos que não se integram a ela, aos que não trilham caminhos de sucesso nas malhas de sua estrutura.

Mas resta discutir, ainda, a própria especificidade do literário, no que diz. respeito aos aspectos formais e ao status da literatura frente a outros discursos e ao meio social. A produção ficcional de Böll está longe de incorter em ativismo político imediatista; há sim, de sua parte, a preocupação com preservar a autonomia do discurso literário.

Nas Preleções de Frankfurt, cle apresenta a idéia de que "o conteúdo de uma obra em prosa é seu pressuposto, é dado”. O que faculta sua análise e compreensão é a forma que assume. "Reunir palavras, estudar a sintaxe, analisar, fundamentar ritmos - dai adviria a resposta para que ritmo, que sintaxe e que vocabulário o humano e o social possuem em nosso país" (ESR2, p. 38). Ou seja: o significado aprecnsível de imediato na enunciação, segundo Böll, oferece-se de modo gratuito a quem a recebe, assim como já se havia oferecido a quem a formulara. O componente ético, entretanto, as opçōes éticas expressas por quem propõe a enunciação - estas podem ser apreendidas pela observação 
dos procedimentos lingüísticos de que resulta uma determinada apresentação formal, e não outra.

Para a literatura, que se debruça especificamente sobre o procedimento de construção formal e faz dele seu objeto, o conteúdo "dado" é assumido de maneira explícita e se multiplica através da construção fíccional. Pelo filtro da subjetividade do escritor, a realidade incorpora também clementos do que nela poderia ser diferente, dos anseios arbitrariamente impostos por quem escreve. E dai advém a importância do "caminho" entre o real apreendido pelo escritor c o real apreendido por quem se depara com sua enunciação, bem como a importância das conseqüências que ele traz consigo.

Um autor não apanha a realidade, ele a tem, ele a cria, e o mistério, também de um romance comparativamente realista, consiste na pouca importância daquilo de real que entrou nele, que possa ter sido processado, modificado e composto em seu interior. Importância, $\mathrm{sim}$, tem aquilo de realidade criada que provém dele e passa a atuar. (ESR2, p. 54)

Interessa não a representação "documental", a mera imitação da realidade imediata; instigante, sim, poderiamos dizer com Luiz Costa Lima, ${ }^{24}$ é o produto multifacetado do "teatro mental" de que resulta o texto de fiç̧ão, e que se realiza plenamente pela apreensão e repercussão do texto na comunidade de leitores.

Sobre essa questão, é essencial no clenco de ensaios poéticos de Böll o conjunto dos Discursos de Wuppertal. No primeiro, de 1958, destaca-se a força da palavra e seu poder concreto de atuação no meio social. Böll caracteriza o papel do escritor face ao poder da palavra: para ele, o escritor independente deve estar sempre atento ao instrumento que utiliza $\mathrm{c}$ às possiveis conseqüências do que diz e escreve. Ao exercer sua atividade, a única instância a que deve estar submetido ć sua própria consciência, sem qualquer atrelamento ao poder constituido na sociedade. Ele é, em si mesmo, uma "instituição" no tecido social, capaz de existir "apenas em uma sociedade livre". (ESR1, p. 305)

Destaque-sc aí a importancia atribuída à subjetividade por Böll. Sua produção integra-se ao projeto moderno da construção do indivíduo como instância última e decisiva na organização da sociedade, e insere-se de modo explícito na discussão sobre a autonomia da criação individual no âmbito das

${ }^{24}$ Cf. COSTA LIMA, Luiz. Sociedade e discurso ficcional. Rio de Janeiro: Guanabara, 1986. A expressão "teatro mental", citada e utilizada por Costa Lima, provém do texto "Stendhal" de Paul Valéry. (In: Oeuvres I, Paris, 1957) 
artes. ${ }^{25}$ A busca da autonomia da voz individual do escritor frente à sociedade estabelecida fundamenta boa parte de sua reflexão poética e boa parte de sua produção ficcional. A derrota do projeto de sociedade para a Alemanha do Pós-guerra ao qual Böll se sentia filiado torna-o cm muitas situações uma voz solitária diante do senso comum que ele entende como ameaçador.

O "Primeiro discurso de Wuppertal", nesse sentido, dedica-se ainda ao problema da construção da verdade, que surge da compatibilidade entre a "consciência" individual e a realidade diante da qual o escritor se encontra. Defende-se um padrão ético pautado pelo respeito à integridade do indivíduo e à manutenção de relações democráticas na sociedade. Não são propugnados valores absolutos, mas uma dinâmica de relações interindividuais. Isso remonta ao compromisso de verdade que Böll atribuíra ao escritor quanto a sua atuação social, especialmente junto a pessoas simples, representadas em Profissāo de fé para uma literatura de escombros pelo padeiro e a jovem trabalhadora.

Quanto ao papel da subjetividade do artista, o "Segundo discurso de Wuppertal", de 1960, apresenta novos argumentos: o artista pretenderia "arrancar da sensação intensa e constante de transitoriedade um farrapo de perenidade" (ESR 1, p. 342). São descartadas quaisquer explicações absolutas em relação à arte, e aponta-sc nela um "resíduo de silêncio" (ESR1, p. 343). Tal componente só se manifestaria quando da fruição da obra, e mesmo aí não seria plenamente apreensivel:

Nem o artista nem o erudito sabe o que faz; um quadro tem tantas vidas quantos os olhares que recaem sobre ele, uma peça musical, tantas quanto a metade do número de ouvidos que a ouvem; a arte existe para ser oferecida à sociedade, mas quem a oferece sabe tão pouco sobre o que faz quanto aquele que a torna sociável, que a torna um elemento da cultura. (ESR1, p. 343)

Ao mesmo tempo que o artista pode contar somente com a própria consciência individual para pautar sua produção, isso se dá através de processos $\mathrm{cm}$ parte inconscicntes e inapreensiveis, haja vista a abrangência social e formal que assumem. A produção artística cstaria além do que se pode prever em relação a cla.

${ }^{25}$ Nesse ponto, é útil a referéncia à reflexão de Luiz Costa Lima sobre a questão: "(...) o veto ao imaginário, a conseqüente domesticação do ficcional, têm sido forças presentes no Ocidente desde os primeiros sinais de descoberta da individualidade moderna, já cm fins da Idade Média. $O$ direito de expressão de um eu, não subordinado previamente aos valores (então teológicos) estabelecidos, aparecia como uma ameaça à propagação da verdade." (COSTA LIMA, op. cit., p. 189) 
Em 1966, no "Terceiro discurso de Wuppertal", Böll volta a assumir o argumento desenvolvido em 1958 sobre arte e liberdade ("o escritor deve submeter-se apenas à sua consciência individual"). Suas formulações, no entanto, são ainda mais incisivas: "de liberdade a arte não precisa, ela é liberdade" (ESR2, p. 228); ela é «a única manifestação reconhecivel da liberdade neste planeta" (idem). E seus limites, cla os desconhece a priori:

Quando ultrapassa os limites (...), quando vai longe demais, só então é que ela acaba percebendo: vai-se abrir fogo contra ela. Quão longe ela pode ir ou deveria ter podido ir, isso ninguém pode dizer de antemão; por isso ela precisa ir longe demais mesmo, para descobrir até onde pode ir, até onde chega a linha de liberdade aceita para ela. (ESR2, p. 228)

Na inconformidade da arte, que não se deixa confundir com desolação, Böll vê o que há de mais formidável nela:

$\mathrm{Na}$ inconformidade da poesia esconde-se um determinado consolo. Repetidas vezes ela mergulha em vão esse tridente [composto por liberdade, caráter constitutivo e inconformidade] no oceano infinito da transitoriedade, para arrancar dele um farrapo que possa perdurar. (...) Mas não é importante, para aquele que a produz, que ela seja perene; o importante é que algo, qualquer coisa possa perdurar sobre esta terra, porque ela, a poesia, é total e completamente desta terra. (ESR2, p. 230)

Como atividade essencialmente humana, a poesia procura livrar-se da constante expectativa que se tem $\mathrm{cm}$ relação a ela: de que se mostre capaz de classificar as coisas e dar-lhes formas definitivas. Ela procura, pelo resgate de um farrapo de perenidade, representar pontualmente apenas um momento autêntico de vida, sua dinamicidade, ambigüidade e irredutibilidade.

É significativa a rcincidência da caracterização do produto artístico como farrapo que almeja durar no tempo: a mesma formulação já estava presente no "Segundo discurso de Wuppertal", escrito seis anos mais cedo (cf. ESR 1, p. 342, citado acima). Mesmo condenada a produzir fragmentos (como quem produz farrapos), a arte caracteriza-se por querer perenizar a vida, transcender seus condicionamentos temporais. Trata-se de uma das típicas aproximações para- 
doxais böllianas: ${ }^{26}$ o farrapo e a transcendência, o fragmento e o absoluto. A aparente limitação da arte, no entanto, revela-se como virtude: o fazer artístico resgata a vida justamente por mostrar-se sensivel aos condicionamentos temporais que a restringiriam. Ao respeitar a complexidade e pluralidade da vida, a arte torna-se capaz de representá-la mais adequada e livremente. Ao contrário do Estado e das Igrejas (que são, segundo Böll, indiferentes a objetos como o amor, a dor, a escuridão e a luz), a arte c a poesia ocupam-se desses "detalhes" de forma intensa.

No caso do amor, por excmplo, a literatura tem desempenhado o papel de "quebrar tabus": "...não porque "entenda" do amor, mas porque o procura, procura insistentemente por ele, mesmo que em vão. Procura aquilo que o Estado $c$ as Igrcjas nunca cntendcram. Estado c Igreja só são capazes de admitir duas possibilidades: ou o casamento ou a prostituição" (ESR2, p. 231). O que fosse além desses limites seria considerado maldito.

Böll vê aí um laço de identificação entre amor e literatura: “... pois no amor há algo daquela de que falamos [a arte]: ele é livre, ordenado e inconformado, ou scja, poesia - e poesia é dinamite para toda a ordem desse mundo" (ESR2, p. 231-32).

A sccicdade organizada, ao reduzir a "trindade" (ESR2, p. 232) que constitui a arte - liberdade, caráter constitutivo e inconformidade - apenas a seu primeiro elemento, transforma-a em mera "hipocrisia degenerada": a arte perde sua dinamicidade e vitalidade, e o que resta conserva apenas uma face mentirosa e superficial, a serviço de interesses que lhe são estranhos. Ao falar de uma "Irindade" que constituiria a arte, Böll apresenta como indissociáveis os aspectos formais éticos da obra artística. A liberdade, como elemento isolado, não sustenta por si só valores estéticos ou éticos, mas deve submeter-se à integridacle da obra: a scu caráter constitutivo ("ordem") e a seu compromisso de crítica à realidade em que é produzida ("inconformidade"). A arte, como tal, precisa levar às últimas conseqüencias os compromissos éticos $\mathrm{e}$ formais determinados pela consciència de quem a produz. O escritor, como sujeito, precisa ser livre para julgar os fatos, independente das estruturas de poder constituidas, mas comprometido com a vida e a dinamicidade das relações humanas.

Como a dinàmica do poder na sociedade esteriliza as relações e impõc restrições aos individuos, torna-se imprescindivel à arte romper os limites que cria para si mesma, já que eles são incorporados pelo gosto e expectativas dominantes. Por isso, em relação à arte, "o objetivo nunca é atingido, e jamais a literatura pode proporcionar tranqüilidade (...). [A arte], que scmpre precisa ir além dos limites, desconhece a tranqüilidade e não a proporciona" (ESR2, p. 232).

26 Sobre a aproximação de elementos contraditórios em Böll, v. KUSCHEL, K.J., "Vielleicht hält sich Gon einige Dichter... ". Literarisch-theologische Porträts. Mainz: Grünewald, 1991, p. 312-13. 
No Ensaio sobre a razão da poesia, de 1973, Böll ressalta o componente de imprevisibilidade presente na literatura, sua irredutibilidade a explicações definitivas. $O$ texto atribui tal componente ao sem-número de informaçōes e à carga histórica que cada palavra traz consigo:

(...) o material "linguagem" não pode ser reduzido a um valor de comunicação objetivo e genericamente compreensível: cada palavra está carregada de muita história e de muita história fantasiosa, de muita história nacional e social, e também de relatividade histórica - tudo isso deveria ser transmitido através dela (...). (ESR3, p. 39)

Pelo uso dessa palavra multifacetada na produção de seus textos, o escritor mergulha na diversidade das relações humanas. Ocupa-se de um intervalo ("Z wischenraum") estabelecido entre seu universo pessoal e o universo que cria, entre a vontade de escrever e a conquista do corpo desconhecido, ao qual atribui vida no momento da escrita. ${ }^{27}$

O intervalo, segundo Böll, pode receber diferentes denominações: "ironia, poesia, Deus, ficção e resistência" (ESR3, p. 39). O termo "resistência", de caráter ético e político, remete à noção de "inconformidade", já mencionada; "Deus" presentifica o viés religioso da reflexão, a tendència bölliana de integrar de forma discreta o aspecto teológico a seu pensamento estético; e a esse pensamento, de maneira mais especifica, integram-se os termos "ironia", "poesia" e "ficção". É do intervalo que poeta e ficcionista devem ocupar-se, ao contrário dos "políticos, ideólogos, teólogos e filósofos", que precisam sempre oferecer soluções acabadas para os problemas. Estes - depreende-se da argumentação de Böll - fixam o ponto de vista de suas análises $\mathrm{cm}$ um único pólo no processo de interação humana (uma teoria, um dogma, uma crença) e apresentam formulações unilaterais com pretensões totalizantes.

Nesse sentido, pode-se entender a presença de "ironia" entre a série de nomes para "intervalo" como referência à ironia romântica: o autor deve estar atento às formulaçōes que escolhe, à materialidade e forma de seu texto; é preciso que submeta tal escolha à própria critica $\mathrm{c}$ a tematize no corpo do texto, assim como suas motivaçōes. Voltar-se criticamente para o próprio discurso é estar atento ao intervalo estabelecido entre sua formulação e o impulso inicial que o origina. É cstar atento ao outro, ao contex to e às condições pessoais que interferem na produção discursiva.

${ }^{27}$ Sobre a noção de intervalo em literatura, v. BARBOSA, João Alexandre. A leitura do internalo. São Paulo: Iluminuras, 1990. 
A atenção ao intervalo constitui a especificidade do poético. Nele reside toda a irredutibilidade da palavra e da criação poética, todas as implicações inefáveis que a palavra traz consigo por estar mergulhada na vida e no dinamismo das relaçōes interpessoais.

Segundo Böll, os intervalos estabelecidos nas relaçôes humanas em geral são esterilizados e apropriados indevidamente pelas respostas prontas das Igrejas, Estados e ideologias. Para ele, a cultura ocidental burguesa, numa atitude de completa arrogância, pretende preencher esses intervalos com regras e teorias. Nossa cultura abandonaria, assim, a humildade intrínseca à realidade humana e ignoraria sua irredutibilidade. Ao impor suas fórmulas, substituiria humildade por humilhação, como teria acontecido no confronto entre ocidentais e índios, na colonização da América. "Foi isso que fizemos com os povos colonizados: transformamos sua humildade, a poesia de sua humildade, $\mathrm{cm}$ humilhação para eles". (ERS3, p. 45)

Por querer preservar o componente de mistério e irredutibilidade que se esconde nos intervalos estabelecidos entre as relações interpessoais, a opção de Böll pela poesia é radical.

Será que é proibido contar com a confiança das pessoas na razão da poesia, e, mais que isso, com que clas a tornem ainda mais forte? Com que não apenas a deixem em paz, mas que também aceitem um pouco de sua paz e do orgulho de sua humildade, que está sempre voltada para baixo e nunca para cima? Nela, na razão da poesia, estão sempre ocultos respeito, cortesia e justiça, e também o desejo de reconhecer e ser reconhecido. (ESR3, p. 45)

O conjunto de reflexōes apresentado permite compreender de que maneira a concepção bölliana de poesia assume-se como eticamente condicionada. E de que maneira, segundo o autor, dá-se a incorporação do componente ético à própria gênese c ontologia do fazer poético. Para Böll, a poesia existe a partir de uma postura de humildade e respeito diante do outro, do diferente. Ou scja, diante da impossibilidade do ser humano de compreender de forma absoluta sua existéncia no mundo e a totalidade dos fatos implícitos em sua relaçāo com os semelhantes. 


\section{Conclusão}

Em um tempo de ensimesmamento e autocentramento da arte, de dissociação entre o fazer artístico e o quotidiano da imensa maioria das pessoas, Heinrich Böll revigora uma possibilidade ancestral da literatura: a elaboração particular de respostas inusitadas às questōes do quotidiano, mas de modo a conferir-lhe vitalidade e força agregadora.

Não se pode dissociar suas considerações poéticas da reflexāo ética que desenvolveu, nem tampouco situar sua obra ficcional de modo adequado, sem que se considere esse aspecto em sua produção. Provocativamente, Böll vinculou o universo da literatura à vida e às questōes concretas do contexto em que cla surge. Preservou-lhe o sentido $\mathrm{c}$ o espaço $\mathrm{cm}$ mcio à comunidade efetiva de leitores, sem restringir a autonomia do escritor $\mathrm{c}$ a importância da livre criação. Tanto essa autonomia quanto a liberdade de criação, porém, ele as condicionou à opção radical pelo outro e à incorporação das limitações do sujeito criador à sua produção, como elemento constitutivo da literatura - e mesmo essencial a ela.

\section{RESUMO}

O presente artigo, ao comentar os principais textos ensaisticos do escritor alemão Heinrich Böll (1917-1985) sobre literatura, proporciona uma visão de conjunto de suas concepções poéticas. Informa, ainda, sobre a situação histórica e cultural em que as mesmas se desenvolveram e procura aproximá-las ao campo de interesse das discussões contemporâneas sobre o assunto. e literatura

Palavras-chave: Heinrich Böll - poética, literatura alemã do Pós-guerra ética

\section{ABSTRACT}

This article comments the main essays taken from the German writer Heinrich Böll's (1917-1985) literature and it presents his literary concepts as a whole. It also presents the historical and cultural context where these concepts appeared and intends to bring them closer to contemporary discussions on this subject. 


\section{REFERÊNCIAS BIBLIOGRÁFICAS}

BARBOSA, João Alexandre. A leitura do intervalo. São Paulo: Iluminuras, 1990. BIRKE, Adolf M. Nation ohne Haus. Deutschland 1945-1961. Berlim: Siedler, 1989. BOLL, Heinrich. Werke. Essaystische Schriften und Reden (Obras completas. Escritos e discursos ensaísticos). 3 v. Colônia: Kiepenheuer und Witsch, 1979. (No texto, os três volumes são indicados, respectivamente, pelas abreviaturas ESR1, ESR2 e ESR3.)

COSTA LIMA, Luiz. Sociedade e discurso ficcional. Rio de Janeiro: Guanabara, 1986.

DURZAK, Manfred (org.). Deutsche Gegenwartsliteratur. Ausgangspositionen und aktuelle Entwicklungen. Stuttgart: Reclam, 1981.

FRIEDRICHSMEYER, Die satirische Kurzprosa Heinrich Bölls. Chapell Hill: The University of North Carolina Press, 1981.

GLASER, Hermann. Kleine Kulturgeschichte der Bundesrepublik Deutschland. $\mathrm{Mu}-$ nique: Carl Hanser, 1991.

GOTTLICHER, Kerstin. Die irdisch-materialistische, menschlich-himmlische Leni : Aspekte der Religion in Heinrich Bölls Roman "Gruppenbild mit Dame". Giessen, 1990. Magisterarbeit - Justus-Liebig-Universität.

GOSTRAU, Stephan. Literatur als Theologieersatz: Heinrich Böll: "Sie sagt, ihr Kuba ist hier und auch ihr Nicaragua ". Frankfurt a. M.: Peter Lang, 1990.

HEHL, Ulrich von; HORTEN, Heinz (orgs.). Der Katholizismus in der Bundesrepublik Deutschland 1945-1980. Eine Bibliographie. Mainz, 1983.

HOFFMANN, Gabriele. Heinrich Böll. Leben und Werk. Munique: Wilhelm Heyne, 1991.

KAFITZ, Dieter. Formtradition und religiöses Ethos - zur Realismuskonzeption Heinrich Bölls. Der Deutschunterricht, Stuttgart, v. 6, dez. 1976.

KONG, Hans; JENS, Walter. Anwälte der Humanität: Thomas Mann, Hermann Hesse, Heinrich Böll. Munique: Kindler, 1989.

KURZ, Paul Konrad. Uber moderne Literatur. 2. ed. Frankfurt a. M.: Josef Knecht, 1976. LEONHARDT, Rudolf Walter. Aufstieg und Niedergang der Gruppe 47. In: DURZAK, 1981, p. 67.

KUSCHEL, Karl-Josef. Heinrich Böll e a visão de uma catolicidade diferente. Síntese, Belo Horizonte, v. 21, n. 67, p. 539-557.

."Vielleicht hält sich Gott einige Dichter...". Literarisch-theologische Porträts. Mainz: Grünewald, 1991.

LETTAU, Reinhardt (org.). Die Gruppe 47. Bericht, Kritik, Polemik. Neuwied: Luchterhand, 1967.

SOETHE, Paulo Astor. "Nele tem-se a impressão de que amargura rima com travessura.' Contribuição bibliográfica ao estudo da recepção de Heinrich Böll no Brasil." Revista de Ciências Humanas, Curitiba, n. 3. 